\title{
Sex Differences in Neurochemical Effects of Dopaminergic Drugs in Rat Striatum
}

\author{
Q David Walker', Rupa Ray' and Cynthia M Kuhn*,' \\ 'Department of Pharmacology and Cancer Biology, Duke University Medical Center, Durham, NC, USA
}

\begin{abstract}
Previous data indicate that dopamine neurotransmission is differently regulated in male and female rats. The purpose of the present study was to investigate the dopamine transporter and autoreceptor as potential loci responsible for this sex difference. Fast cyclic voltammetry at carbon-fiber microelectrodes was used to monitor changes in electrically evoked levels of extracellular dopamine in the striata of anesthetized male and female rats before and after administration of an uptake inhibitor, a dopamine $D_{2}$ antagonist, or a $D_{3} / D_{2}$ agonist. Administration of $40 \mathrm{mg} / \mathrm{kg}$ cocaine ip increased electrically-evoked extracellular dopamine concentrations in both sexes, but to a significantly greater extent in female striatum at the higher stimulation frequencies. The typical antipsychotic, haloperidol, increased dopamine efflux in both sexes but the effect was twice as large in the female striatum. The $D_{3} / D_{2}$ agonist quinpirole induced an unexpected, transient increase in dopamine efflux following high-frequency stimulation only in females, and evoked dopamine was higher in females across this entire time course. More detailed analysis of cocaine effects revealed no fundamental sex differences in the interaction of cocaine with DAT in vivo or in synaptosomes. These results indicate that nigrostriatal dopamine neurotransmission in the female rat is more tightly regulated by autoreceptor and transporter mechanisms, perhaps related by greater autoreceptor control of DAT activity. Thus, baseline sex differences in striatal dopamine regulation induce different pharmacologic responses. These results contribute to understanding sex differences in stimulant-induced locomotor activity in rats and may have broader implications for neurologic disorders and their pharmacotherapies in humans.

Neuropsychopharmacology (2006) 3 I, I 193- 1202. doi: I0.1038/sj.npp. I3009 I5; published online 12 October 2005
\end{abstract}

Keywords: dopamine release; dopamine uptake; sex differences; voltammetry; cocaine

\section{INTRODUCTION}

Central dopaminergic systems mediate the reinforcing effects of drugs of abuse and are perturbed in many neurological disorders including schizophrenia, Parkinson's disease, and attention deficit disorder (Berridge and Robinson, 1998; Seeman and Kapur, 2000; Berke and Hyman, 2000; Solanto, 2002). Sex differences in several of these disorders have been reported. For instance, certain aspects of cocaine taking and addiction are more severe in women including prevalence of cocaine dependence in adolescence (Kandel et al, 1997), age and severity of use at intake (Robbins et al, 1999), and cocaine-induced craving (Kosten et al, 1993; Robbins et al, 1999). In contrast to stimulant addiction, women are somewhat protected from Parkinson's disease relative to men (Bower et al, 1999;

*Correspondence: Dr CM Kuhn, Department of Pharmacology and Cancer Biology, Room 100-B, Research Park Building 2, Box 3813, Duke University Medical Center, Durham, NC 27710, USA, Tel: + I 919684 8828, Fax: + I919 681 8609, E-mail: ckuhn@acpub.duke.edu Received 23 December 2004; revised 16 August 2005; accepted 17 August 2005

Online publication: I September 2005 at http://www.acnp.org/citations/ Npp090 1050406 / 2/default.pdf
Baldereschi et al, 2000), and the age of onset of schizophrenia is about 6 years later in women than men (Lindamer et al, 1997; Hafner et al, 1998; Leung and Chue, 2000). This set of clinical findings suggests that underlying sex differences in dopaminergic function exist in humans. Three studies using three different radioligands all showed that women have more dopamine transporters than men in the striatum (Lavalaye et al, 2000; Staley et al, 2001; Mozley et al, 2001).

Animal studies including those from this laboratory also demonstrate the existence of sex differences in dopaminergic function that contribute to significant sex differences in behavior. Our laboratory and others have shown that indirect dopamine agonists like cocaine induce greater behavioral (Bowman and Kuhn, 1996; Walker et al, 2001a) and neuroendocrine (Walker et al, 2001b) effects in female than male rats. Female rats trained to self-administer cocaine on a progressive ratio schedule have higher break points than males (Roberts et al, 1987; Carroll et al, 2002), and acquisition, maintenance and reinstatement of cocaine self-administration are greater in female rats (Lynch and Carroll, 1999, 2000; Lynch et al, 2000; Hu et al, 2004). However, Caine et al (2004) using a relatively hightraining dose of cocaine found that male rats acquired 
self-administration earlier than females. This study found no sex or ovarian hormone effects on maintenance of cocaine self-administration using a fixed ratio five schedule of reinforcement.

Female and male rats also respond differently to directacting dopamine $D_{2}$ ligands. Male rats were more sensitive than females to acute and sub-chronic haloperidol impairment of escape-avoidance behavior (Parra et al, 1999; Arenas et al, 1999). Campbell et al (1988) showed that female Long-Evans rats were more sensitive than males to haloperidol-induced catalepsy. Weekly administration of haloperidol produced a greater hypersensitivity to haloperidol-induced catalepsy in female than male rats, although daily administration induced a tolerance in females but not males (Fujii and Ikeda, 1982). The $D_{2}$ agonists apomorphine and quinpirole have also been reported to induce sex differences in spontaneous behavior in rats (Savageau and Beatty, 1981; van Hartesveldt, 1997; Schindler and Cannona, 2002).

The basis of the substantially greater dopamine release and uptake rates in the striatum of female rats (Walker et al, 2000) remains unknown. The dopamine transporter (DAT) and/or the release-and uptake-regulating autoreceptor (Rouge-Pont et al, 2002) could be important molecules for regulating sex differences in extracellular dopamine. These baseline differences in dopaminergic neurotransmission could mediate sex differences in behavioral responses to dopaminergic drugs and potentially contribute to the sex differences in addiction and neurologic disease risk. The following studies probed the contributions of DAT and the autoreceptor to sex differences in dopamine by determining changes in dopamine overflow induced by protypical ligands for these sites. We have more extensively probed sex differences in the interactions of cocaine and DAT to better understand sex differences in the disregulation of dopaminergic neurotransmission.

\section{MATERIALS AND METHODS}

\section{Subjects}

Adult male and female $\mathrm{CD}$ rats were purchased from Charles River Laboratories (Raleigh, NC, USA). They were segregated by sex and were housed in plastic cages under a 12:12 light: dark cycle with lights on at 0600 . Food and water were provided ad libitum. Animals were moved to the testing facility and weighed the day before observations. All animals were tested between 60 and 90 days of age, 2-3 weeks after shipment on average. Females were used without regard to estrous state because we have shown that dopamine uptake and release do not vary across the female estrous cycle (Walker et al, 2000). Animal care was in accordance with the Guide for the Care and Use of Laboratory Animals (NIH publication 865-23, Bethesda, MD, USA) and approved by the Institutional Animal Care and Use Committee.

\section{Electrochemistry}

Voltammetry procedures were similar to previously published methods (Walker et al, 2000). Fast-scan cyclic voltammetry (Millar et al, 1985) was conducted with an
EI-400 potentiostat (Ensman Instrumentation, Bloomington, IN, USA). Locally written computer software triggered the potentiostat to apply a triangle wave $(-0.4$ to $1 \mathrm{~V}$ and back, at $300 \mathrm{~V} / \mathrm{s}$ ) to a carbon fiber electrode. Cyclic voltammograms were recorded every $100 \mathrm{~ms}$ and digitized using a DMA Labmaster board (Scientific Solutions, Solon, OH). Carbon-fiber microcylinder electrodes prepared from $7 \mu \mathrm{m}$ diameter T-300 fibers (Amoco, Greenville, SC, USA.) were used in the in vivo experiments (Cahill et al, 1996) along with a $\mathrm{Ag} / \mathrm{AgCl}$ reference (BAS Inc., West Lafayette, IN).

Changes in extracellular dopamine were determined by monitoring the current over a $200 \mathrm{mV}$ window at the peak oxidation potential for dopamine. Background subtracted cyclic voltammograms were used to identify the electroactive substance as dopamine. These voltammograms were obtained by subtracting voltammograms collected during stimulation from those collected during baseline recording. To convert oxidation current to dopamine concentration, electrodes were calibrated with dopamine standard solutions in a flow injection system following experimental use.

\section{In Vivo Procedures}

Rats were anesthetized with urethane ( $1.5 \mathrm{~g} / \mathrm{kg}$ i.p.) and positioned in a stereotaxic apparatus (David Kopf Instruments, Tujunga, CA). Body temperature was maintained at $37^{\circ} \mathrm{C}$ with a Deltaphase Isothermal Pad (Braintree Scientific, Braintree, MA). A bipolar stimulating electrode (Plastics One Inc., Roanoke, VA) was positioned in the medial forebrain bundle (MFB) and electrical stimulation parameters were $300 \mu \mathrm{A}$, biphasic, $2 \mathrm{~ms}$ each phase. The stereotaxic coordinates (in $\mathrm{mm}$ ) anteroposterior (AP) and mediolateral (ML) from the bregma and dorsoventral (DV) from the dura that follow are based on a brain atlas (Paxinos and Watson, 1986). The stimulating electrode was placed at: $-4.6 \mathrm{AP},+1.4 \mathrm{ML},-7.5$ to $-9.0 \mathrm{DV}$. For the cocaine and quinpirole experiments the carbon-fiber microelectrode was directed at the center of the caudate $(+1.2 \mathrm{AP}, 2.0 \mathrm{ML},-4.5$ to $-6.2 \mathrm{DV})$. Haloperidol effects were determined at medial and lateral locations within the striatum because the density of dopamine $D_{2}$ receptors has been reported to vary across its medial-lateral axis (Falardeau and Di Paolo, 1987; Joyce et al, 1985). The medial and lateral coordinates for haloperidol experiments were: +1.2 AP, 1.4 or $2.7 \mathrm{ML},-4.5$ to $-6.2 \mathrm{DV}$, respectively. The electrode placed in the lateral aspect of the caudate was angled toward the midline at $12^{\circ}$.

The locations of the stimulating and working electrodes were optimized to give maximal dopamine responses. A $60 \mathrm{~Hz} 120$-pulse stimulation was applied to evoke extracellular concentrations of dopamine 10-fold greater than the $K_{\mathrm{m}}$ to measure $V_{\max }$ directly from the slope of the decay curve (Wightman et al, 1988). Dopamine efflux induced by frequencies from $10,20,30,40,50$, and $60 \mathrm{~Hz}$ was recorded. Haloperidol and quinpirole experiments used 120 pulse train duration at each frequency and post-drug recordings occurred at 5-10 min intervals beginning $10 \mathrm{~min}$ after drug administration. A shorter stimulus train duration (30 pulses) was used in the cocaine experiments to enable more frequent data collection so that all frequency responses could be recorded over the time of cocaine's 
peak behavioral effects (Walker et al, 2001a). Since sex differences in extracellular striatal dopamine concentrations develop with increasing stimulus train duration, the shorter stimulus duration also served to minimize baseline sex differences (Walker et al, 2000). Thirty stimulus pulses were applied at each frequency except for $40 \mathrm{~Hz}$, which used 28 pulses. Immediately after the final baseline data collection, rats were administered $40 \mathrm{mg} / \mathrm{kg}$ cocaine i.p, to saturate dopamine transporters. At $2.5 \mathrm{~min}$ post cocaine injection the $20 \mathrm{~Hz}$ stimulations commenced and were made at $2.5 \mathrm{~min}$ intervals until $20 \mathrm{~min}$ postinjection. Postcocaine responses to stimulations at the other frequencies were recorded between 20 and 50 min following cocaine administration.

\section{Synaptosomal Uptake}

Male and female CD rats (Charles River), aged 70-90 days, were killed by decapitation and the brains were rapidly removed. Dorsal striata were dissected on ice, weighed, and homogenized with a glass-teflon homogenizer using five to seven strokes by hand in 10 volumes of $0.32 \mathrm{M}$ sucrose, $25.0 \mathrm{mM}$ tris and $10.0 \mu \mathrm{M}$ iproniazid phosphate. Homogenates were centrifuged at $1000 \mathrm{~g}$ for $10 \mathrm{~min}$. The resulting supernatants were centrifuged for $20 \mathrm{~min}$ at $17500 \mathrm{~g}$. The P2 pellet was resuspended with a glass-teflon homogenizer using two to three strokes by hand in 100 volumes of modified Kreb's-bicarbonate buffer. This buffer consisted of $118 \mathrm{mM} \mathrm{NaCl}, 5.4 \mathrm{mM} \mathrm{KCl}, 1.3 \mathrm{mM} \mathrm{CaCl}_{2}, 25 \mathrm{mM} \mathrm{NaHCO}_{3}$, $1.2 \mathrm{mM} \mathrm{NaH} \mathrm{PO}_{4} \cdot \mathrm{H}_{2} \mathrm{O}, 1.2 \mathrm{mM} \mathrm{MgCl}, 11.1 \mathrm{mM}$ dextrose, $2.0 \mu \mathrm{M}$ ascorbic acid, and $1.0 \mu \mathrm{M}$ iproniazid phosphate to inhibit monoamine oxidase activity. The buffer was bubbled with $95 \% \mathrm{O}_{2} / 5 \% \mathrm{CO}_{2}$ and the $\mathrm{pH}$ was adjusted to 7.4 .

The synaptosomes $(100 \mu \mathrm{l}$ in $1 \mathrm{ml}$ total incubation volume) were preincubated with buffer and cocaine for $5 \mathrm{~min}$ in a shaking $37^{\circ} \mathrm{C}$ water bath. The various cocaine solutions were serially diluted from a $10 \mathrm{mM}$ stock solution. Uptake was initiated with the addition of $50 \mathrm{nM}\left[{ }^{3} \mathrm{H}\right]$ dopamine (New England Nuclear, Natick, MA). Synaptosomes from one male and one female rat were run in each assay $(N=4)$. Nonspecific binding was determined in duplicate tubes kept on ice. Tubes were incubated for $4 \mathrm{~min}$ in a $37^{\circ} \mathrm{C}$ shaking water bath. Uptake was terminated by the addition of $4 \mathrm{ml}$ of ice-cold Kreb's-bicarbonate buffer followed by rapid vacuum filtration over GF/B glass fiber filter paper. Samples were then washed two more times with $4 \mathrm{ml}$ of ice-cold buffer. Radioactivity was counted using liquid scintillation spectrometry. Protein was determined by the method of Bradford.

\section{Data Analysis}

For the cocaine experiment the dynamic changes of extracellular dopamine evoked by electrical stimulation were modeled as a balance between dopamine release and uptake (Wightman et al, 1988; May et al, 1988; Wightman and Zimmerman, 1990). The equation employed to extract kinetic parameters is $\mathrm{d}[\mathrm{DA}] / \mathrm{d} t=f[\mathrm{DA}]_{\mathrm{p}}-V_{\max } /\left(\left(K_{\mathrm{m}} /[\mathrm{DA}]\right)\right.$ +1 ) where $f$ is the frequency of stimulation, $[D A]_{p}$ is the concentration of dopamine released per stimulus pulse, and $V_{\max }$ and $K_{\mathrm{m}}$ are Michaelis-Menten parameters for the maximal uptake rate and the affinity of the transporter, respectively. Non-linear curve fitting using a simplex algorithm calculated $V_{\max }, K_{\mathrm{m}}$, and [DA] from in vivo data at each frequency from 20 to $60 \mathrm{~Hz}$ (Wu et al, 2001b). All three parameters were typically allowed to float in this analysis, although occasionally $V_{\max }$ was fixed to the value determined from the slope of the clearance phase of $60 \mathrm{~Hz} 2 \mathrm{~s}$ overflow curves where $[\mathrm{DA}] \gg K_{\mathrm{m}}(\mathrm{Wu}$ et al, 2001b).

Where applicable, data are expressed as the mean \pm SEM and $N$ is the number of rats. The effects of cocaine on dopamine overflow were analyzed using three-way ANOVA (sex by frequency $\times$ treatment). Effects of cocaine and sex on changes of in vivo kinetic parameters were also analyzed by two-way ANOVA. Sex differences in cocaine effects on evoked dopamine overflow were determined by ANOVA with repeated measures. Differences in haloperidol responses in the medial and lateral striatum were determined by paired $t$-test and then medial and lateral electrode responses were averaged per rat. Effects of sex and frequency on percent haloperidol changes in dopamine efflux were analyzed by ANOVA with repeated measures. The effect of sex on maximal extracellular dopamine elicited by $60 \mathrm{~Hz}$ stimulations following quinpirole administration was analyzed by ANOVA with repeated measures on time after injection. Post hoc analysis used the Newman-Keuls Multiple Comparison Test. Differences were considered to be significant when $p<0.05$.

Cocaine inhibition of synaptosomal dopamine uptake data was fitted using a one-site competition model (Prism 3.3, Graphpad Software, San Diego, CA). Sex differences in $\mathrm{IC}_{50}$ 's and maximal dopamine uptake (determined in tubes without cocaine) were analyzed by paired $t$-tests.

\section{Drugs and Reagents}

(-) Cocaine $\mathrm{HCl}$ was obtained from NIDA through the Research Triangle Institute. Cocaine solutions were prepared fresh in $0.9 \%$ saline and injected i.p. ( \pm ) Quinpirole (R.B.I., Natick, MA) was injected subcutaneously at $0.5 \mathrm{mg} /$ $\mathrm{kg}$ in a saline vehicle. Haloperidol (Sigma, St Louis, MO, USA) was prepared in $0.1 \%$ tartaric acid and injected subcutaneously at $0.5 \mathrm{mg} / \mathrm{kg}$. The dose volume for each drug was $1 \mathrm{ml} / \mathrm{kg}$.

\section{RESULTS}

Sex-Dependent Changes in Dopamine Efflux Induced by Dopamine Transporter and Autoreceptor Ligands

Cocaine. Figure 1 shows voltammetric recordings of electrically stimulated dopamine overflow in the dorsal striatum of anesthetized male and female rats at baseline and following $40 \mathrm{mg} / \mathrm{kg}$ cocaine i.p. Short stimulus trains of 30 pulses were employed so that overflow at all frequencies including $60 \mathrm{~Hz}$ would be approximately equal in males and females at baseline (Walker et al, 2000). The maximal effect of cocaine occurred within $15 \mathrm{~min}$ after injection (data not shown). Increasing stimulation frequency induced greater dopamine overflow and systemic cocaine administration increased overflow at each frequency. Cocaine induced proportionally larger increases in the overflow in female striatum at higher frequencies. 
Male

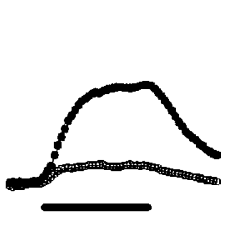

$10 \mathrm{~Hz}$

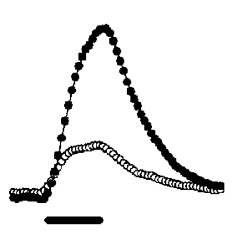

$20 \mathrm{~Hz}$

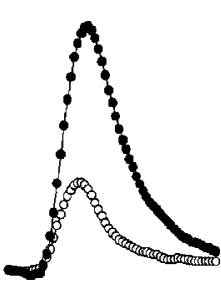

$30 \mathrm{~Hz}$

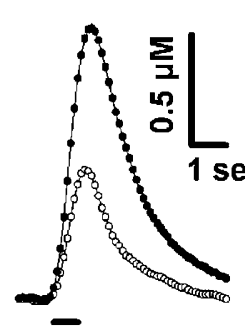

$40 \mathrm{~Hz}$

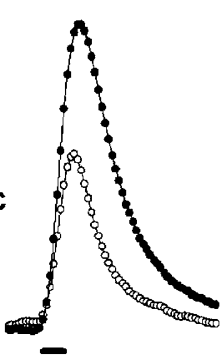

$50 \mathrm{~Hz}$

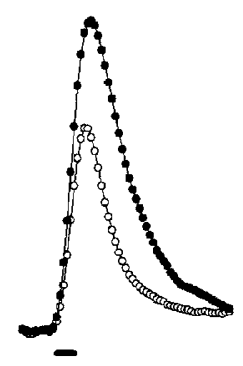

$60 \mathrm{~Hz}$

Female
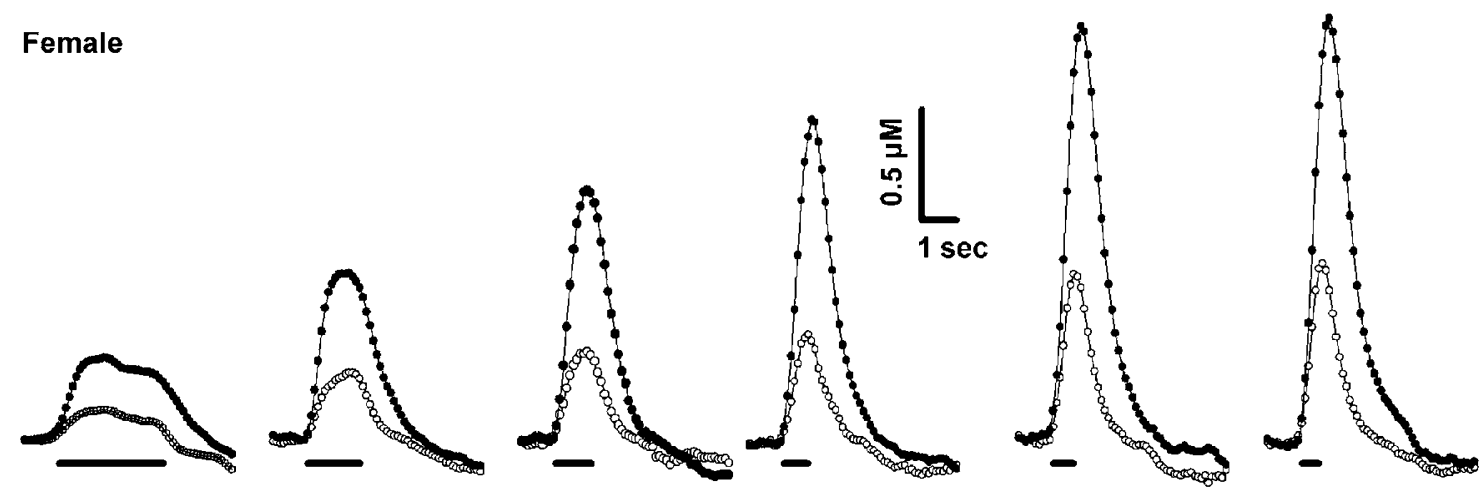

Figure I Voltammetric recordings in anesthetized rat striata before and after $40 \mathrm{mg} / \mathrm{kg}$ cocaine. Dopamine release was evoked by 30 pulse electrical stimulations $(300 \mu \mathrm{A})$ of the medial forebrain bundle at the frequencies indicated. Cyclic voltammograms obtained from each recording matched those of a standard dopamine solution obtained from the same electrodes in vitro following the experiment. The frequency of stimulation is indicated between the male and female recordings. The identical scale bars for each rat apply to all frequencies. The open circles represent baseline dopamine concentrations determined at 100 msec intervals and the filled circles show the effects of cocaine on stimulated dopamine efflux in each rat. The lines under the recordings indicate application of the electrical stimulation. Cocaine effects were determined between 15 and 50 min after i.p. injection.

Figure 2 shows group averages of data obtained as in Figure 1. In all, 30 pulse stimulus trains elicited the same extracellular dopamine concentrations in male and female striata prior to cocaine administration. Therefore, the main effect of sex did not reach statistical significance $(p=0.08)$. Cocaine increased dopamine overflow three to five-fold in males and females and ANOVA confirmed a significant overall effect of treatment $(F(1,12)=106$, $p<0.001)$. Stimulation frequency exerted a significant overall effect on dopamine efflux $(p<0.001)$ and significantly interacted with sex $(\mathrm{F}(5,57)=2.59, p=0.035)$. A significant interaction of sex, frequency, and treatment $(\mathrm{F}(5,55)=2.39, p=0.049)$ was also found. Subsequent ANOVA excluding baseline data showed that sex differences in cocaine effects on dopamine efflux were frequency dependent ( $\operatorname{sex} \times$ frequency, $\mathrm{F}(5,56)=3.07, p=0.016)$. Post hoc analysis indicated that maximal dopamine concentrations elicited by 50 and $60 \mathrm{~Hz}$ stimulations following cocaine administration were significantly greater in females than in males $(p<0.05)$.

Haloperidol. Figure 3 shows voltammetric recordings of electrically stimulated dopamine overflow in the dorsal striatum of anesthetized male and female rats before and after $0.5 \mathrm{mg} / \mathrm{kg}$ haloperidol i.p. Haloperidol was maximally effective within $15 \mathrm{~min}$ after injection (data not shown). All the data in Figure 3 were determined at the medial site

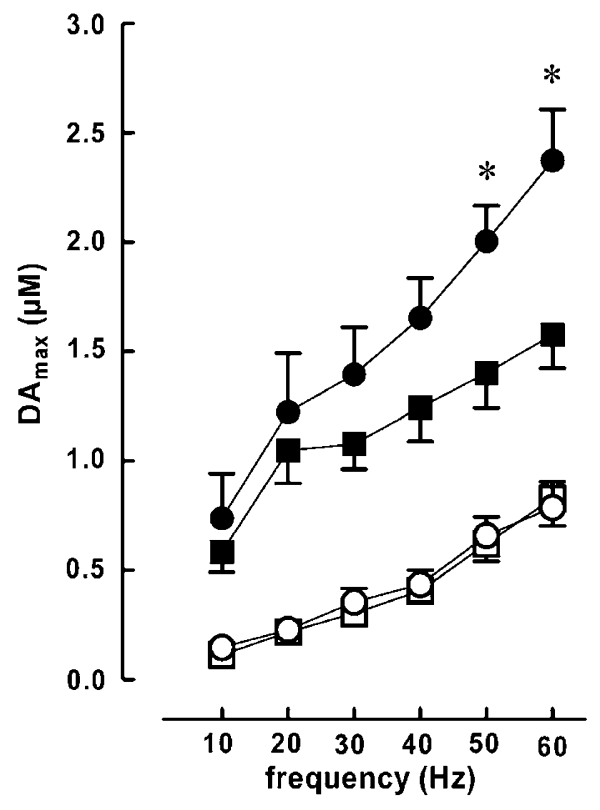

Figure 2 Sex differences in the effects of $40 \mathrm{mg} / \mathrm{kg}$ cocaine in rat striata in vivo. Maximal dopamine overflow (DA $\mathrm{Dax}_{\text {max }}$ ) was determined from recordings obtained as described in Figure I and averaged across groups of male $(N=8)$ and female $(N=8)$ rats. Square symbols represent data from males while circles represent female data. Open symbols represent baseline data and filled symbols represent after cocaine measurements. *significantly greater than males at the same frequency $(p<0.05)$. 


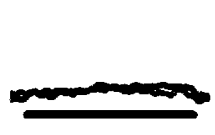

$10 \mathrm{~Hz}$

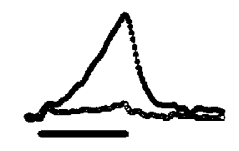

$20 \mathrm{~Hz}$

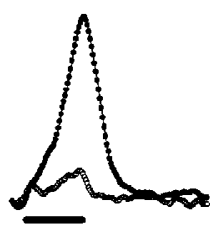

$30 \mathrm{~Hz}$

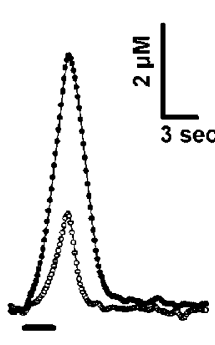

$40 \mathrm{~Hz}$

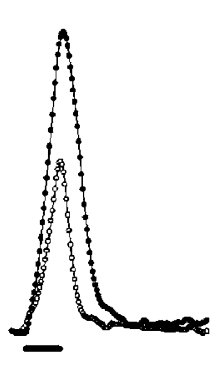

$50 \mathrm{~Hz}$

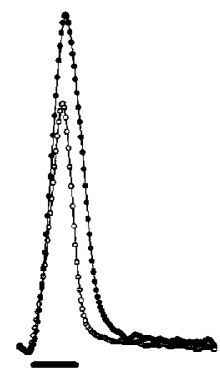

$60 \mathrm{~Hz}$

Female
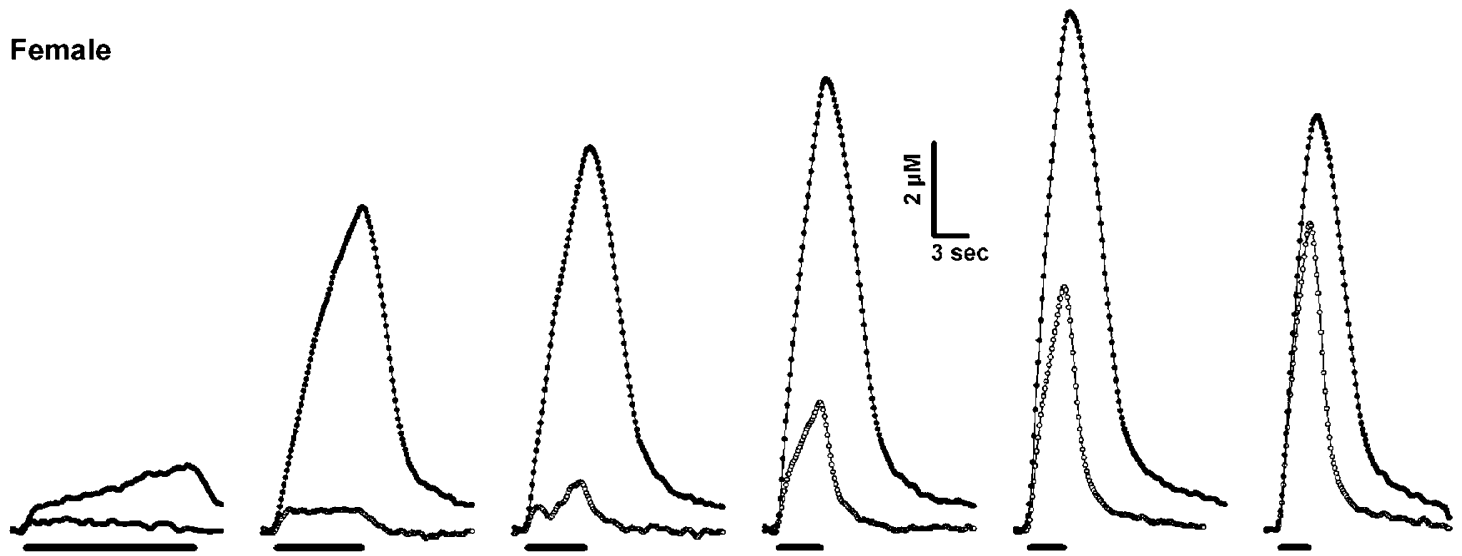

Figure 3 Voltammetric recordings in anesthetized rat striata before and after $0.5 \mathrm{mg} / \mathrm{kg}$ haloperidol. Data were collected as in Figure I except that I20 pulse electrical stimulations of the medial forebrain bundle were used. The lines under the recordings indicate application of the electrical stimulation. Data are from a single male and a single female rat at the medial electrode location. Haloperidol effects were determined between 15 and 70 min after i.p. injection.

and show that haloperidol-induced increases in dopamine overflow were greater in the female.

Haloperidol had identical effects on dopamine overflow at both the medial and lateral sites in the striatum and therefore, the average haloperidol effect per rat is shown for clarity. Figure 4 shows group averages of data obtained at both sites in the striatum as in Figure 3. Data are expressed as percent effect of haloperidol relative to the baseline to emphasize the most robust relative changes in extracellular dopamine. The greatest change in dopamine overflow induced by haloperidol was at $20 \mathrm{~Hz}$ in both sexes. Twoway ANOVA indicated that frequency exerted a significant effect on haloperidol-induced changes $(p<0.001)$ but the main effect of sex did not reach statistical significance $(p=0.06)$. The effect of haloperidol in each sex differed by frequency as indicated by a significant interaction of sex and frequency $(\mathrm{F}(5,51)=3.8, p=0.008)$.

Quinpirole. Figure 5 shows effects of administration of $0.5 \mathrm{mg} / \mathrm{kg}$ quinpirole s.c. in the striata of anesthetized male and female rats. The recordings on the left (top and bottom) show dopamine efflux at baseline following typical $60 \mathrm{~Hz} 2 \mathrm{~s}$ electrical stimulations. Quinpirole increased dopamine efflux $10 \mathrm{~min}$ after injection in both rats but was somewhat more effective in this female. Evoked dopamine was slightly higher or equal to baseline at 30 and $60 \mathrm{~min}$, respectively, in the female. In contrast, evoked dopamine decreased slightly below baseline levels in the male at 30 and $60 \mathrm{~min}$. A rigorous examination of quinpirole effects at other frequencies was not conducted in all rats (as in the previous experiments) in order to describe completely the time

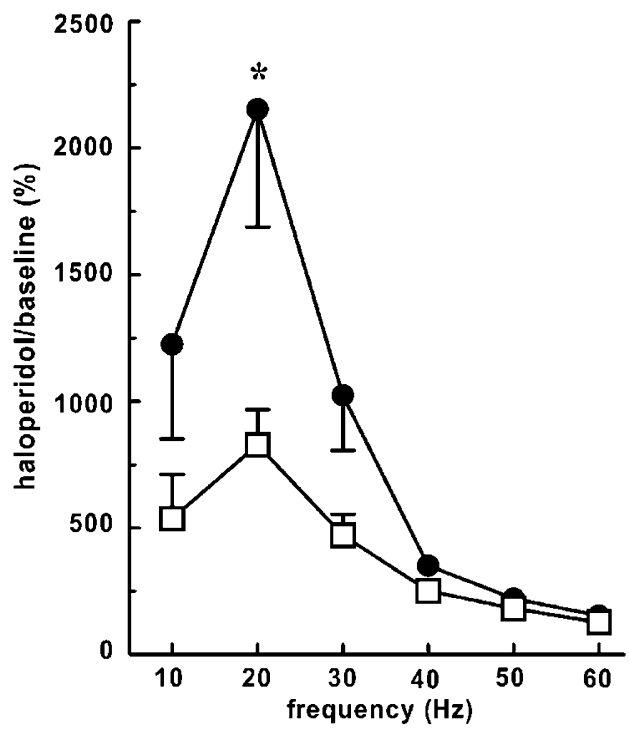

Figure 4 Sex differences in the effects of $0.5 \mathrm{mg} / \mathrm{kg}$ haloperidol in rat striata in vivo. Maximal dopamine overflow (DA $\mathrm{Dax}_{\text {max }}$ ) was determined from recordings obtained as described in Figure 3 and averaged across groups of male $(N=5)$ and female $(N=4)$ rats. The $[D A]_{\max }$ after haloperidol was divided by that obtained at baseline and shown as the percentage. The average response per rat is shown because the drug effect was the same at the medial and lateral electrode locations. ANOVA indicated significant effects of frequency and the interaction of sex and frequency. *significantly greater than males at the same frequency $(p<0.05)$

course of this unexpected increase at $60 \mathrm{~Hz}$. Stimulated efflux was determined at a single, representative low frequency of $20 \mathrm{~Hz}$ in all rats. The two panels on the right 


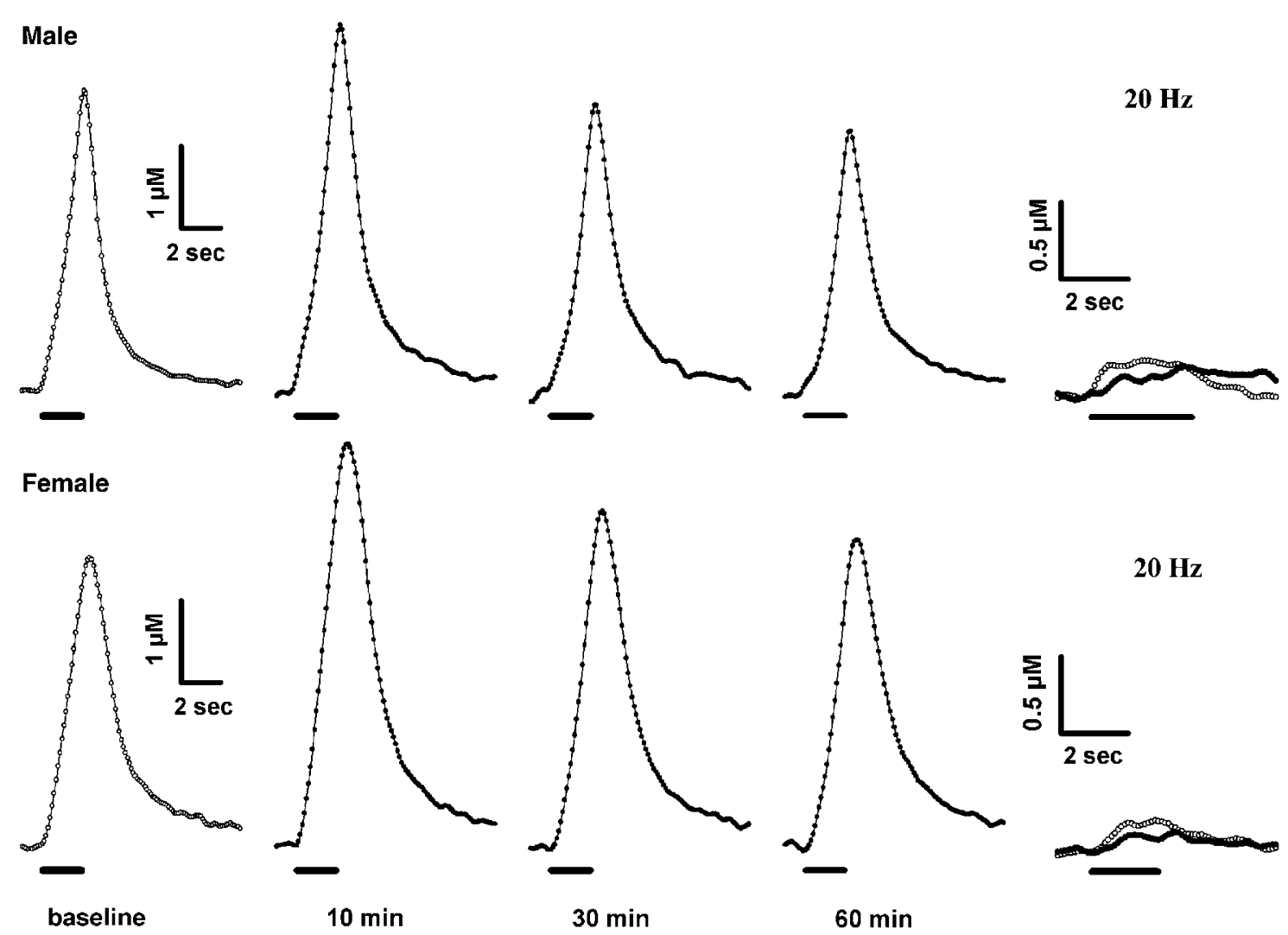

Figure 5 Time course of quinpirole effects on dopamine overflow following $60 \mathrm{~Hz}$ stimulations. Voltammetric recordings in striatum of anesthetized male and female rats following $60 \mathrm{~Hz} 120$ pulse electrical stimulations of the medial forebrain bundle. A baseline recording, prior to drug administration, and recordings 10,30 and $60 \mathrm{~min}$ after $0.5 \mathrm{mg} / \mathrm{kg}$ quinpirole s.c. are shown. The two recordings on the right side of the figure illustrate that quinpirole never increased dopamine overflow induced by $20 \mathrm{~Hz}$ stimulations at any point in the time course, in contrast to the effects at $60 \mathrm{~Hz}$. For clarity the scale was increased for the $20 \mathrm{~Hz}$ recordings and the scale bars for each sex are identical at each frequency.

of Figure 5 show dopamine efflux following $20 \mathrm{~Hz}$ stimulations in the same animals before and after quinpirole. Quinpirole attenuated dopamine efflux at $20 \mathrm{~Hz}$ in both these rats and never increased electrically stimulated efflux at $20 \mathrm{~Hz}$ in any rat at any time after administration. Quinpirole decreased dopamine levels evoked by $20 \mathrm{~Hz}$ stimulations to an average of $63 \pm 6 \%$ of baseline in males and $53 \pm 5 \%$ in females by $50 \mathrm{~min}$ after injection (not significant, $p=0.75$ ).

The average effects of quinpirole on dopamine efflux evoked by $60 \mathrm{~Hz}$ stimulations on male $(N=6)$ and female $(N=5)$ rats are shown in Figure 6. Maximal evoked dopamine concentrations over the entire time course were significantly greater in the female striatum $(F(1,49)=5.1$, $p=0.049$ ). The effects of quinpirole in all rats varied over the one hour time course $(\mathrm{F}(4,49)=13.7, p<0.001)$ and the interaction of sex and time was significant $(F(4,49)=2.7$, $p=0.049)$. Post hoc analysis showed that quinpirole increased evoked dopamine at 10 and $20 \mathrm{~min}$ in the females $(p<0.05)$ and males and females were significantly different at 10,20 , and $30 \mathrm{~min}(p<0.05)$.

\section{Probing Sex Differences in Cocaine Interactions with the Dopamine Transporter}

Kinetic modeling of baseline and postcocaine data indicated that cocaine induced a large increase in the $K_{\mathrm{m}}$ in both male

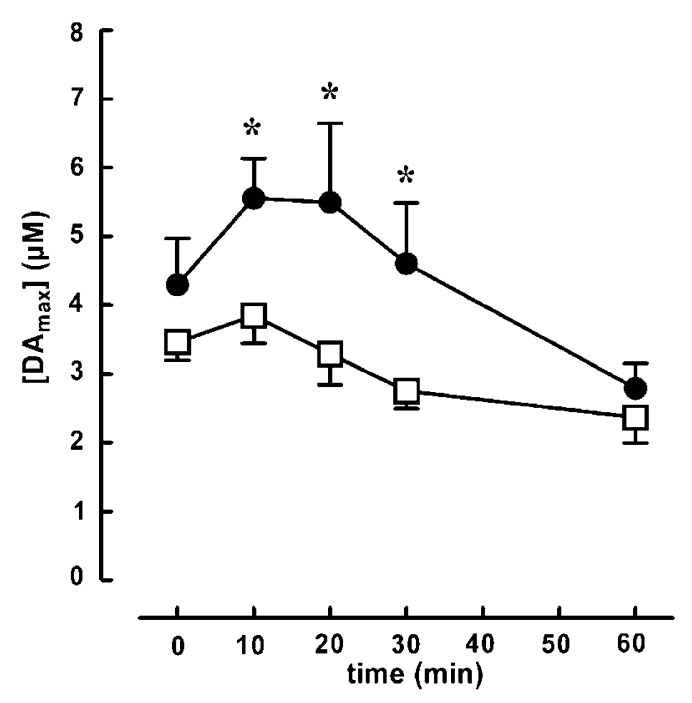

Figure 6 Sex differences in the time course of quinpirole effects on dopamine overflow in anesthetized rat striatum. Maximal dopamine overflow $\left(D A_{\max }\right)$ was determined from data as described in Figure 5. The average $[D A]_{\max }$ before administration of quinpirole was $3.4 \pm 0.2$ (males, $N=6$ ) and $4.3 \pm 0.7 \mu \mathrm{M}$ (females, $N=5)(p=0.3$ ) Significant effects of sex and time and their interaction were found Quinpirole increased evoked dopamine 10 and 20 min after injection in females $(p<0.05)$. *significantly greater than males at the same time $(p<0.05)$. 
and female striata and minor, insignificant increases in the release term $\left([\mathrm{DA}]_{\mathrm{p}}\right)$ (see Table 1 ). Cocaine significantly increased the $K_{\mathrm{m}}$ in both male and female rats $(\mathrm{F}(1,30)=36.5, p<0.001)$ and no sex difference existed for $K_{\mathrm{m}}$ after cocaine $(p=0.76)$. Cocaine did not change $[\mathrm{DA}]_{\mathrm{p}}$ significantly $(p=0.13)$. $[\mathrm{DA}]_{\mathrm{p}}$ values were significantly larger in females than in males $(\mathrm{F}(1,30)=13.7, p=0.001)$. $V_{\max }$ values were also greater in the female striatum overall $(\mathrm{F}(1,30)=17.2, p<0.001)$ and cocaine did not alter the maximal uptake rate $(p=0.44)$. There were no interactions between sex and drug treatment on any of the three kinetic parameters indicating a similar mechanism of action for cocaine in both sexes.

Possible sex differences in interactions of cocaine with dopamine transporters were investigated in vitro. Figure 7 shows that cocaine was equally potent for inhibition of dopamine uptake in striatal synaptosomes from both males and females $(N=4)$. The average $\mathrm{IC}_{50}$ s determined from one-site, sigmoidal regression analysis in individual experi-

Table I In Vivo Dopamine Release and Uptake Kinetics

\begin{tabular}{lccccc}
\hline & \multicolumn{2}{c}{ Baseline } & & \multicolumn{2}{c}{ Cocaine $\mathbf{( 4 0 ~ \mathbf { ~ m g } / \mathbf { k g } )}$} \\
\cline { 2 - 3 } \cline { 6 - 6 } Parameter & Male & Female & & Male & Female \\
\hline$[\mathrm{DA}]_{p}(\mathrm{nM}) *$ & $60 \pm 8$ & $99 \pm 13$ & & $72 \pm 7$ & $125 \pm 19$ \\
$V_{\max }(\mu \mathrm{M} / \mathrm{s}) *$ & $2.07 \pm 0.27$ & $3.99 \pm 0.49$ & & $1.76 \pm 0.19$ & $3.60 \pm 0.74$ \\
$K_{m}(\mu \mathrm{M})^{\#}$ & $0.2 \pm 0.02$ & $0.2 \pm 0.02$ & & $1.03 \pm 0.13$ & $1.12 \pm 0.29$
\end{tabular}

Values represent the mean \pm SEM for eight rats per group.

*Significant overall effect of sex $(p<0.005)$.

${ }^{\#}$ Significant overall cocaine effect $(p<0.00 \mathrm{I})$.

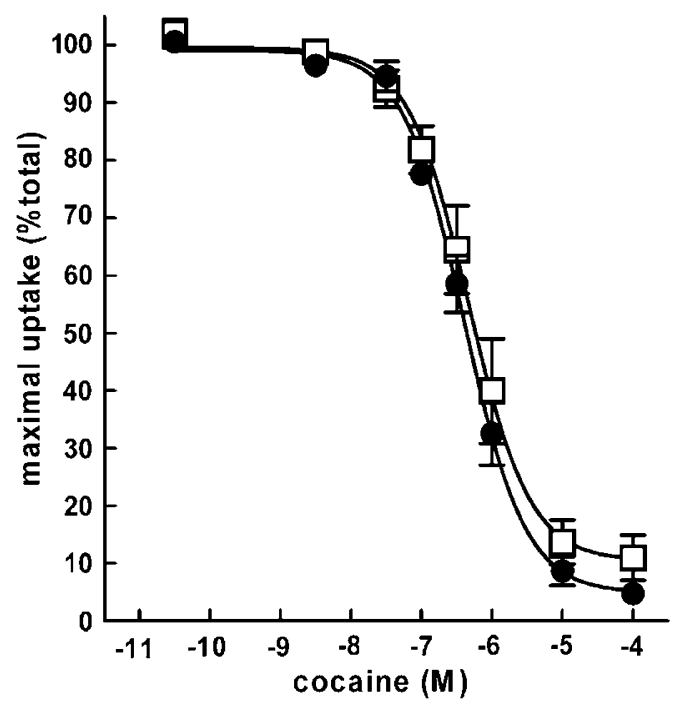

Figure 7 Cocaine inhibition of dopamine uptake in rat striatal homogenates. P2 synaptosomal fractions were prepared from freshly dissected male and female striata $(\mathrm{N}=4)$ and exposed to $50 \mathrm{nM}{ }^{3} \mathrm{H}$ dopamine for four min in the presence of different concentrations of cocaine. The maximal uptake rates for female and male rats in the absence of any inhibitor were determined $(19.8 \pm 7.2$ and $11.0 \pm 3.6 \mathrm{pmol}$ dopamine/mg protein/min, respectively) and cocaine inhibition was then expressed as a percentage of the maximal uptake. The $\mathrm{IC}_{50}$ 's were $358 \pm 32$ and $359 \pm 37 \mathrm{nM}$ in female and male striatum, respectively. ments in male and female synaptosomes were virtually identical, $359 \pm 37$ and $358 \pm 32 \mathrm{nM}$, respectively. These data are expressed as percent of maximal uptake in each sex because uptake tended to be higher in synaptosomes from female than male rats $(19.8 \pm 7.2$ and $10.9 \pm 3.5 \mathrm{pmol} / \mathrm{mg}$ protein/min, respectively, $p=0.18$ ). Thus, the sex differences observed in vivo did not result from sex differences in molecular interactions of cocaine with DAT.

\section{DISCUSSION}

The present results suggest that pharmacologic disruption of either DAT or the dopamine autoreceptor causes exaggerated changes in regulation of extracellular dopamine in the female striatum compared to that in males. While cocaine increased dopamine overflow three-to-five fold in the striatum of anesthetized male and female rats, it induced significantly more dopamine efflux in females than in males, despite equivalent levels following 30 pulse baseline stimulations. Antagonism of the $D_{2}$ autoreceptor by haloperidol induced more dopamine overflow in female than male rats. Evoked dopamine was also increased only in the female striatum at early time points following administration of the $D_{2}$ agonist quinpirole. These differences in dopaminergic function may partly explain sex differences in cocaine-stimulated locomotion and other behaviors.

Sex differences in cocaine-induced dopamine overflow likely reflect the same processes that mediate previously observed sex differences in basal dopamine overflow following $60 \mathrm{~Hz}$ but not $20 \mathrm{~Hz}$ stimulations (Walker et al, 2000). Rates of uptake and release are significantly greater in the female striatum, but the net of these competing processes in both sexes produces equivalent extracellular dopamine concentrations at $20 \mathrm{~Hz}$ stimulations. As less time is available for uptake to occur in between stimulus pulses at high-stimulation frequency, extracellular dopamine saturates uptake and rise rapidly (Wightman and Zimmerman, 1990). The greater female release rate overwhelms its own rapid uptake rate faster than the analogous competition in the male with slower rates for both processes. We hypothesize that the sex difference in extracellular dopamine following cocaine occurred mainly at the upper range of frequencies because uptake inhibition from cocaine accentuated the normal propensity of the female striatum to produce higher concentrations of extracellular dopamine than the male striatum when stimulated at high frequency. The synaptosomal uptake data confirmed the in vivo modeling results showing that cocaine did not have any preferential effect at the dopamine transporter in female tissue.

The greater increase in dopamine after cocaine in females is consistent with the theoretical simulations of $\mathrm{Wu}$ et al (2001a) which show that cocaine should induce greatest percent increases in dopamine efflux in regions where release rates are lower and uptake rates are higher. Analysis of present baseline data from the cocaine-treated rats indicated that $V_{\max }$ was $93 \%$ higher in females than in males, and $[D A]_{p}$ was $65 \%$ higher in females. Although the greater release rate in the female striatum could serve to attenuate the greater percent increase in the female striatum induced by cocaine, the disparity in $V_{\max }$ favors the greater 
increase in the female striatum. These data suggest that $V_{\max }$ more tightly regulates extracellular dopamine in female striatum and inhibition of the more tightly regulated system leads to greater disruption, that is, more extracellular dopamine following cocaine administration. The sex differences are statistically significant only at high firing frequencies, which exhibit linear increases in extracellular dopamine caused by release overwhelming uptake (Wightman and Zimmerman, 1990). An important caveat is that these frequencies are substantially higher than those seen physiologically in neurons identified unequivocally as dopaminergic (Bunney et al, 1973; Grace and Bunney, 1983).

A number of reports suggest that certain aspects of cocaine taking and addiction are more severe in women (Griffin et al, 1989; Kosten et al, 1993; Mendelson et al, 1991). Human data show that cocaine cues induced craving more in women than in men (Robbins et al, 1999) and cocaine craving overall is generally greater in women (Elman et al, 2001). Dopamine neurons fire more rapidly (burst) when they are activated by stimuli with reward salience (Schultz, 2001). An interesting speculation is that the present data showing that cocaine induces sex differences in extracellular dopamine at high frequencies may be related to human sex differences in cocaine craving and addiction.

The present results showing robust increases in electrically stimulated dopamine levels after haloperidol that were greater in female than in male rats confirm previous studies of enhanced dopamine overflow after D2 antagonist treatment (Wiedemann et al (1992). The effect of haloperidol showed a significant sex difference at $20 \mathrm{~Hz}$, in contrast to the effect of cocaine that was apparent at the high frequency range. Haloperidol exerted similar effects in medial and lateral striatum suggesting that the reported medial-lateral gradient of $D_{2}$ receptors in the rat striatum (Falardeau and Di Paolo, 1987; Joyce et al, 1985) is not due to presynaptic autoreceptors that represent only a small fraction of all striatal $D_{2}$ receptors.

Haloperidol increases electrically stimulated dopamine signals by blocking presynaptic autoreceptors that inhibit dopamine release and stimulate uptake (Meiergerd et al, 1993; Wolf and Roth, 1987, 1990; Starke et al, 1989; Cass and Gerhardt, 1994; Wu et al, 2002). These mechanisms play a primary role in the increased basal extracellular dopamine levels that result from $D_{2}$ antagonist administration (Imperato and Di Chiara, 1985). The present results are consistent with previous findings that female rats are more sensitive to haloperidol-induced catalepsy (Campbell et al, 1988) and have a higher striatal $D_{2}$ receptor density (Bosse and DiPaolo, 1996; Bazzett and Becker, 1994). Further, they suggest that females may also possess more presynaptic $D_{2}$ receptors.

The present data showing that haloperidol increases evoked dopamine release more in female rats may be relevant to observations in humans treated with antipsychotics. Women schizophrenics require lower doses of antipsychotics and respond more quickly and better than men (Seeman, 2002). Tardive dyskinesia is also more common and more severe in women than men treated with neuroleptics (Seeman, 1985; Yassa and Jeste, 1992). We postulate that enhanced dopamine release by equivalent doses could produce more depolarization blockade in women leading to both greater therapeutic benefit and a greater risk of side effects (Grace and Bunney, 1986; Boye and Rompre, 2000). Nondopaminergic mechanisms could also contribute to these differences. Sex and estrous cyclerelated differences in tissue neurotensin concentrations in rats have been reported (Kinkead et al, 2000) and could also be involved in sex differences in severity of schizophrenic pathology (Garver et al, 1991).

The sex- and frequency-specific effects on evoked dopamine concentrations after quinpirole are also consistent with enhanced autoreceptor function in females. Quinpirole increased extracellular dopamine concentrations transiently in the female striatum following $60 \mathrm{~Hz}$ stimulations. A possible explanation for this increase in dopamine efflux may be a decrease in cell firing due to somatic autoreceptor stimulation resulting in enhanced accumulation of vesicular, releasable dopamine. The sex difference is consistent with the report that low doses of quinpirole $(0.03$ and $0.1 \mathrm{mg} / \mathrm{kg}$ ) depress locomotor activity in males but not in females (Schindler and Cannona, 2002). This modest effect seen only in females could reflect tighter uptake regulation by autoreceptors. Chiodo and Caggiula (1983) have similarly shown that estradiol increases the sensitivity of nigral $D_{2}$ autoreceptors on Type $\mathrm{A}$ and $\mathrm{B}$ neurons that change the firing frequency of these neurons.

In summary, this work shows that pharmacologic antagonism of both DAT and the autoreceptor produces exaggerated responses in extracellular dopamine regulation in the striatum of female rats. These responses could be related through autoreceptor control of DAT activity. Stimulation of $D_{2}$ autoreceptors increases dopamine uptake (Meiergerd et al, 1993; Cass and Gerhardt, 1994; Wu et al, 2002). $D_{2}$ receptor knockout mice have only half the dopamine clearance rate of wild-type mice although DAT expression is identical (Dickinson et al, 1999). Greater autoreceptor stimulation of uptake in females could produce the greater $V_{\max }$ in the female striatum observed in our prior report (Walker et al, 2000) and the current study. Thus, sex differences in the regulation of dopamine neurotransmission by the dopamine autoreceptor and DAT may contribute to sex differences in addiction and neurologic diseases.

\section{ACKNOWLEDGEMENTS}

This work was supported by Grant \#DA09079. The authors have no financial or other conflict of interest that would bias these results.

\section{REFERENCES}

Arenas MC, Vinader-Caerols C, Monleon S, Parra A, Simon VM (1999). Dose dependency of sex differences in the effects of repeated haloperidol administration in avoidance conditioning in mice. Pharmacol Biochem Behav 62: 703-709.

Baldereschi M, Di Carlo A, Rocca WA, Vanni P, Maggi S, Perissinotto E et al (2000). Parkinson's disease and parkinsonism in a longitudinal study: two-fold higher incidence in men. ILSA Working Group. Italian Longitudinal Study on Aging. Neurology 55: 1358-1363. 
Bazzett TJ, Becker JB (1994). Sex differences in the rapid and acute effects of estrogen on striatal D2 dopamine receptor binding. Brain Res 637: 163-172.

Berke JD, Hyman SE (2000). Addiction, dopamine, and the molecular mechanisms of memory. Neuron 25: 515-532.

Berridge KC, Robinson TE (1998). What is the role of dopamine in reward: hedonic impact, reward learning, or incentive salience? Brain Res Rev 28: 309-369.

Bosse R, DiPaolo T (1996). The modulation of brain dopamine and GABAA receptors by estradiol: a clue for CNS changes occurring at menopause. Cell Molec Neurobiol 16: 199-212.

Bower JH, Maraganore DM, McDonnell SK, Rocca WA (1999). Incidence and distribution of parkinsonism in Olmsted County, Minnesota, 1976-1990. Neurology 52: 1214-1220.

Bowman BP, Kuhn CM (1996). Age-related differences in the chronic and acute response to cocaine in the rat. Dev Psychobiol 29: 597-611.

Boye SM, Rompre PP (2000). Behavioral evidence of depolarization block of dopamine neurons after chronic treatment with haloperidol and clozapine. J Neurosci 20: 1229-1239.

Bunney BS, Walters JR, Roth RH, Aghajanian GK (1973). Dopaminergic neurons: effect of antipsychotic drugs and amphetamine on single cell activity. J Pharmacol Exp Therapeut 185: 560-571.

Cahill PS, Walker QD, Finnegan JM, Mickelson GE, Travis ER, Wightman RM (1996). Microelectrodes for the measurement of catecholamines in biological systems. Anal Chem 68: 3180-3186.

Caine SB, Bowen CA, Yu G, Zuzga D, Negus SS, Mello NK (2004). Effect of gonadectomy and gonadal hormone replacement on cocaine self-administration in female and male rats. Neuropsychopharmacology 29: 929-942.

Campbell A, Baldessarini RJ, Cremens MC (1988). Dose-catalepsy response to haloperidol in rat: effects of strain and sex. Neuropharmacology 27: 1197-1199.

Carroll ME, Morgan AD, Lynch WJ, Campbell UC, Dess NK (2002). Intravenous cocaine and heroin self-administration in rats selectively bred for differential saccharin intake: phenotype and sex differences. Psychopharmacology 161: 304-313.

Cass WA, Gerhardt GA (1994). Direct in vivo evidence that D2 dopamine receptors can modulate dopamine uptake. Neurosci Lett 176: 259-263.

Chiodo LA, Caggiula AR (1983). Substantia nigra dopamine neurons: alterations in basal discharge rates and autoreceptor sensitivity induced by estrogen. Neuropharmacology 22: 593-599.

Dickinson SD, Sabeti J, Larson GA, Giardina K, Rubinstein M, Kelly MA et al (1999). Dopamine D2 receptor-deficient mice exhibit decreased dopamine transporter function but no changes in dopamine release in dorsal striatum. J Neurochem 72: $148-156$.

Elman I, Karlsgodt KH, Gastfriend DR (2001). Gender differences in cocaine craving among non-treatment-seeking individuals with cocaine dependence. Am J Drug Alcohol Abuse 27: 193-202.

Falardeau P, Di Paolo T (1987). Regional effect of estradiol on rat caudate-putamen dopamine receptors: lateral-medial differences. Neurosci Lett 74: 43-48.

Fujii T, Ikeda H (1982). Sex difference in the development of hypersensitivity or tolerance to haloperidol in the rat. Jap $J$ Pharmacol 32: 247-254.

Garver DL, Bissette G, Yao JK, Nemeroff CB (1991). Relation of Csf neurotensin concentrations to symptoms and drug response of psychotic-patients. Am J Psychiatry 148: 484-488.

Grace AA, Bunney BS (1983). Intracellular and extracellular electrophysiology of nigral dopaminergic-neurons. 1. Identification and characterization. Neuroscience 10: 301-315.

Grace AA, Bunney BS (1986). Induction of depolarization block in midbrain dopamine neurons by repeated administration of haloperidol: analysis using in vivo intracellular recording. J Pharmacol Exp Ther 238: 1092-1100.

Griffin ML, Weiss RD, Mirin SM, Lange U (1989). A comparison of male and female cocaine abusers. Arch Gen Psychiatry 46: 122-126.

Hafner H, an der Heiden W, Behrens S, Gattaz WF, Hambrecht M, Loffler W et al (1998). Causes and consequences of the gender difference in age at onset of schizophrenia. Schizophr Bull 24: 99-113.

Hu M, Crombag HS, Robinson TE, Becker JB (2004). Biological basis of sex differences in the propensity to self-administer cocaine. Neuropsychopharmacology 29: 81-85.

Imperato A, Di Chiara G (1985). Dopamine release and metabolism in awake rats after systemic neuroleptics as studied by transstriatal dialysis. J Neurosci 5: 297-306.

Joyce JN, Loeschen SK, Marshall JF (1985). Dopamine D-2 receptors in rat caudate-putamen: the lateral to medial gradient does not correspond to dopaminergic innervation. Brain Res 338: $209-218$.

Kandel D, Chen K, Warner LA, Kessler RC, Grant B (1997). Prevalence and demographic correlates of symptoms of last year dependence on alcohol, nicotine, marijuana and cocaine in the U.S. population. Drug Alcohol Depend 44: 11-29.

Kinkead B, Lorch SM, Owens MJ, Nemeroff CB (2000). Sexand estrous cycle-related differences in the effects of acute antipsychotic drug administration on neurotensin-containing neurons in the rat brain. J Pharmacol Exp Therap 295: 205-211.

Kosten TA, Gawin FH, Kosten TR, Rounsaville BJ (1993). Gender differences in cocaine use and treatment response. J Subst Abuse Treat 10: 63-66.

Lavalaye J, Booij J, Reneman L, Habraken JB, van Royen EA (2000). Effect of age and gender on dopamine transporter imaging with [123I]FP- CIT SPET in healthy volunteers. Eur J Nucl Med 27: 867-869.

Leung A, Chue P (2000). Sex differences in schizophrenia, a review of the literature. Acta Psychiatr Scand Suppl 401: 3-38.

Lindamer LA, Lohr JB, Harris MJ, Jeste DV (1997). Gender, estrogen, and schizophrenia. Psychopharmacol Bull 33: 221-228.

Lynch WJ, Arizzi MN, Carroll ME (2000). Effects of sex and the estrous cycle on regulation of intravenously self-administered cocaine in rats. Psychopharmacology (Berlin) 152: 132-139.

Lynch WJ, Carroll ME (1999). Sex differences in the acquisition of intravenously self-administered cocaine and heroin in rats. Psychopharmacology 144: 77-82.

Lynch WJ, Carroll ME (2000). Reinstatement of cocaine selfadministration in rats: sex differences. Psychopharmacology (Berlan) 148: 196-200.

May LJ, Kuhr WG, Wightman RM (1988). Differentiation of dopamine overflow and uptake processes in the extracellular fluid of the rat caudate nucleus with fast-scan in vivo voltammetry. J Neurochem 51: 1060-1069.

Meiergerd SM, Patterson TA, Schenk JO (1993). D2 receptors may modulate the function of the striatal transporter for dopamine: kinetic evidence from studies in vitro and in vivo. J Neurochem 61: 764-767.

Mendelson JH, Weiss R, Griffin M, Mirin SM, Teoh SK, Mello NK et al (1991). Some special considerations for treatment of drug abuse and dependence in women. NIDA Res Monogr 106: 313-327.

Millar J, Stamford JA, Kruk ZL, Wightman RM (1985). Electrochemical, pharmacological and electrophysiological evidence of rapid dopamine release and removal in the rat caudate nucleus following electrical stimulation of the median forebrain bundle. Eur J Pharmacol 109: 341-348.

Mozley LH, Gur RC, Mozley PD, Gur RE (2001). Striatal dopamine transporters and cognitive functioning in healthy men and women. Am J Psychiatry 158: 1492-1499. 
Parra A, Arenas MC, Monleon S, Vinader-Caerols C, Simon VM (1999). Sex differences in the effects of neuroleptics on escapeavoidance behavior in mice: a review. Pharmacol Biochem Behav 64: 813-820.

Paxinos G, Watson C (1986). The Rat Brain in Stereotaxic Coordinates. Academic Press: New York.

Robbins SJ, Ehrman RN, Childress AR, O’Brien CP (1999). Comparing levels of cocaine cue reactivity in male and female outpatients. Drug Alcohol Depend 53: 223-230.

Roberts DC, Dalton JC, Vickers GJ (1987). Increased selfadministration of cocaine following haloperidol: effect of ovariectomy, estrogen replacement, and estrous cycle. Pharmacol Biochem Behav 26: 37-43.

Rouge-Pont F, Usiello A, Benoit-Marand M, Gonon F, Piazza PV, Borrelli E (2002). Changes in extracellular dopamine induced by morphine and cocaine: crucial control by D2 receptors. J Neurosci 22: 3293-3301.

Savageau MM, Beatty WW (1981). Gonadectomy and sex differences in the behavioral responses to amphetamine and apomorphine of rats. Pharmacol Biochem Behav 14: 17-21.

Schindler CW, Cannona GN (2002). Effects of dopamine agonists and antagonists on locomotor activity in male and female rats. Pharmacol Biochemis Behav 72: 857-863.

Schultz W (2001). Reward signaling by dopamine neurons. Neuroscientist 7: 293-302.

Seeman MV (1985). Sex and schizophrenia. Can J Psychiatry 30: 313-315.

Seeman MV (2002). The role of sex hormones in psychopathology: focus on schizophrenia. Prim Care 29: 171-182, viii.

Seeman P, Kapur S (2000). Schizophrenia: more dopamine, more D2 receptors. Proc Natl Acad Sci USA 97: 7673-7675.

Solanto MV (2002). Dopamine dysfunction in AD/HD: integrating clinical and basic neuroscience research. Behav Brain Res 130: 65-71.

Staley JK, Krishnan-Sarin S, Zoghbi S, Tamagnan G, Fujita M, Seibyl JP et al (2001). Sex differences in [123I] $\beta$-CIT SPECT measures of dopamine and serotonin transporter availablity in healthy smokers and nonsmokers. Synapse 41: 275-284.

Starke K, Gothert M, Kilbinger H (1989). Modulation of neurotransmitter release by presynaptic autoreceptors. Physiol Rev 69: 864-989.

van Hartesveldt C (1997). Temporal and environmental effects on quinpirole-induced biphasic locomotion in rats. Pharmacol Biochem Behav 58: 955-960.
Walker QD, Cabassa J, Kaplan KA, Li S, Haroon J, Spohr HA et al (2001a). Sex differences in cocaine-stimulated motor behavior: Disparate effects of gonadectomy. Neuropsychopharmacology 25: 118-130.

Walker QD, Francis R, Cabassa J, Kuhn CM (2001b). Effect of ovarian hormones and estrous cycle on stimulation of the hypothalamo-pituitary-adrenal axis by cocaine. J Pharmacol Exp Ther 297: 291-298.

Walker QD, Rooney MB, Wightman RM, Kuhn CM (2000). Dopamine release and uptake are greater in female than male rat striatum as measured by fast cyclic voltammetry. Neuroscience 95: 1061-1070.

Wiedemann DJ, Garris PA, Near JA, Wightman RM (1992). Effect of chronic haloperidol treatment on stimulated synaptic overflow of dopamine in the rat striatum. J Pharmacol Exp Ther 261: 574-579.

Wightman RM, Amatore C, Engstrom RC, Hale PD, Kristensen EW, Kuhr WG et al (1988). Real-time characterization of dopamine overflow and uptake in the rat striatum. Neuroscience 25: 513-523.

Wightman RM, Zimmerman JB (1990). Control of dopamine extracellular concentration in rat striatum by impulse flow and uptake. Brain Res Rev 15: 135-144.

Wolf ME, Roth RH (1987). Dopamine autoreceptors. In: Creese I, Fraser CM (eds). Receptor Biochemistry Methodology: Dopamine Receptors. Alan R Liss: New York. pp 45-96.

Wolf ME, Roth RH (1990). Autoreceptor regulation of dopamine synthesis. Ann NY Acad Sci 604: 323-343.

Wu Q, Reith ME, Kuhar MJ, Carroll FI, Garris PA (2001a). Preferential increases in nucleus accumbens dopamine after systemic cocaine administration are caused by unique characteristics of dopamine neurotransmission. J Neurosci 21: 6338-6347.

Wu Q, Reith ME, Walker QD, Kuhn CM, Carroll FI, Garris PA (2002). Concurrent autoreceptor-mediated control of dopamine release and uptake during neurotransmission: an in vivo voltammetric study. J Neurosci 22: 6272-6281.

Wu Q, Reith ME, Wightman RM, Kawagoe KT, Garris PA (2001b). Determination of release and uptake parameters from electrically evoked dopamine dynamics measured by real-time voltammetry. J Neurosci Methods 112: 119-133.

Yassa R, Jeste DV (1992). Gender differences in tardive dyskinesia: a critical review of the literature. Schizophr Bull 18: 701-715. 